Marquette University

e-Publications@Marquette

Chemistry Faculty Research and Publications

Chemistry, Department of

$1-1-2015$

\title{
Structural Classification of Metal Complexes with Three-Coordinate Centres
}

Timothy L. Davis

Winston-Salem State University

Joshua A. Watts

Winston-Salem State University

Kenneth J. Brown

Winston-Salem State University

Jeewantha S. Hewage

Marquette University, jeewantha.hewage@marquette.edu

Alexander Richard Treleven

Marquette University

See next page for additional authors

Accepted version. Dalton Transactions, Vol. 44 (2015): 15408-15412. DOI. (C) 2015 The Royal Society of Chemistry. Used with permission 


\section{Authors}

Timothy L. Davis, Joshua A. Watts, Kenneth J. Brown, Jeewantha S. Hewage, Alexander Richard Treleven, Sergey V. Lindeman, and James R. Gardinier 


\title{
Structural Classification of Metal Complexes with Three-Coordinate Centres $^{\dagger}$
}

\author{
Timothy L. Davis \\ Department of Chemistry, Winston-Salem State University, \\ Winston-Salem, NC \\ Joshua L. Watts \\ Department of Chemistry, Winston-Salem State University, \\ Winston-Salem, NC \\ Kenneth J. Brown \\ Department of Chemistry, Winston-Salem State University, \\ Winston-Salem, NC \\ Jeewantha S. Hewage \\ Department of Chemistry, Marquette University, \\ Milwaukee, WI \\ Alexander R. Treleven \\ Department of Chemistry, Marquette University, \\ Milwaukee, WI \\ Sergey V. Lindeman \\ Department of Chemistry, Marquette University, \\ Milwaukee, WI
}




\author{
James R. Gardinier \\ Department of Chemistry, Marquette University, \\ Milwaukee, WI
}

\begin{abstract}
Attempts to describe the geometry about three-coordinate silver(I) complexes have proven difficult because interatomic angles generally vary wildly and there is no adequate or readily available classification system found in the literature. A search of the Cambridge Structural Database shows that complexes formed between any metal centre and three non-metal donors (18 001 examples) usually adopt geometries that are quite different than ideal 'textbook' extremes of either trigonal planar ( 4\% with $a=\beta=\gamma=120 \pm$ $\left.2^{\circ}\right)$, T-shaped $\left(\sim 0.05 \%\right.$ with $\left.a=180 \pm 2^{\circ}, \beta=\gamma=90 \pm 2^{\circ}\right)$, or trigonal pyramidal $\left(\sim 0.3 \%\right.$ with $\left.a=\beta=y=110 \pm 2^{\circ}\right)$. Moreover, there are multiple variations of "Y-type" and "other" shapes that require elaboration. Thus, to assist in future structural descriptions, we developed a classification system that spans all known and yet-to-be-discovered three-coordinate geometries. A spreadsheet has also been constructed that utilizes the "shape-space" approach to extract the structural description from a user input of three angles about a tri-coordinate centre and the number of atoms in a plane. The structures of two silver(I) complexes of new $\mathrm{N}$-donor ligands $\mathrm{p}$ $\mathrm{NH}_{2} \mathrm{C}_{6} \mathrm{H}_{4} \mathrm{C}_{6} \mathrm{H}_{4} \mathrm{CH}(\mathrm{pz}=$ pyrazol-1-yl)2, L1, and 2-ferrocenyl-4,5-di(2pyridyl)imidazole, L2, illustrate the utility of this classification system.
\end{abstract}

The classification of structures is fundamental to general and inorganic chemistry. Since the number of ligand atoms bound to (and their symmetry about) a metal centre governs the properties of metal complexes, structures are generally first sorted according to the coordination number of the metal. For each coordination number there are limiting geometries whereby the ligating atoms occupy vertex positions in a polygon or a regular polyhedron ("high-symmetry" points in $2 \mathrm{D}$ or $3 \mathrm{D}$ space). ${ }^{1}$ It is common that the observed structure of a metal complex has a geometry that lies somewhere between the "high-symmetry" limits. For this reason, a host of structural parameters or indices have been developed in attempts to describe how distorted an actual complex is relative to the limiting geometries for a given coordination number. For example, the twist angle, $\theta$, between opposing trigonal faces in six-coordinate structures can be manipulated to give a "Т6" parameter $=\theta / 60$ that varies between 1 for

Dalton Transactions, Vol 44 (2015): pg. 15408-15412. DOI. This article is @ Royal Society of Chemistry and permission has been granted for this version to appear in e-Publications@Marquette. Royal Society of Chemistry does not grant permission for this article to be further copied/distributed or hosted elsewhere without the express permission from Royal Society of Chemistry. 
an octahedron and 0 for a trigonal prism. ${ }^{2}$ Similarly, Addison's fivecoordinate index, $T_{5}=(\beta-a) / 60(\beta$ and $a$ are the two largest basal angles) gives a value of 1 for a trigonal bipyramid $(\beta=180, a=120)$ and $a$ value of 0 for a square pyramid $(\beta=a=180) \cdot{ }^{3}$ In 2007, Houser offered a four-coordinate index $\mathrm{T}_{4}=[360-(a+\beta)] / 141$ ( $a$ and $\beta$ are the two largest angles) that gives a value of 1 for tetrahedron and of 0 for a square planar geometry. ${ }^{4}$ Recently, $\mathrm{T}_{4}$ was modified by Kubiak and coworkers with an asymmetry parameter $T_{\delta}=T_{4}(\beta / a)$ to better distinguish between distorted sawhorse and pinched tetrahedral geometries. ${ }^{5}$ Our recent foray into silver(I) complexes of heteroditopic ligands ${ }^{6}$ has resulted in the structural characterization of numerous derivatives with three-coordinate (3C) metal centres for which we wanted to accurately describe by using a structural index. To our dismay, we could not find reference in the literature to any such " $\mathrm{T}_{3}$ " parameter or related structural index despite the propensity of silver(I) (or, for that matter, of other main group, d-block, or f-block complexes), to exhibit $3 \mathrm{C}$ metal centres. In attempts to develop such a parameter it immediately became evident that this is not a trivial problem. First, the limiting structures of $3 \mathrm{C}$ complexes are not well defined. Textbooks most often cite $3 \mathrm{C}$ structures as being either trigonal planar, T-shape, or trigonal pyramidal. ${ }^{7}$ Less frequently, there is reference to a "Y-shape". ${ }^{8}$ While the angles for the first two structure types are well defined, the angles of a trigonal pyramid $\left(\leq 109.5^{\circ}\right)$ or a "Y-shape" are not. For the latter, multiple types of $Y$ shapes seem to be prevalent (vide infra). Second, it is noted that the complexity of the various $T_{n}$ formula increases with decreasing $n$ because there are fewer interatomic angles to use as a reference and, since there is more space around the metal, structures can adopt a larger number of limiting structures of both planar and nonplanar varieties, as noted above. Third, it is extremely difficult to use only angular values and develop a single $\mathrm{T}_{3}$ parameter that describes both planar and nonplanar structures, in part, because of the convention of reporting obtuse rather than reflex angles (even in planar structures). Especially problematic are planar structures like that of $\mathrm{ClF}_{3},{ }^{9} \mathrm{PhICl}_{2},{ }^{10}$ or $\mathrm{CF}_{3} \mathrm{ICl}_{2}{ }^{11}$ whose sum of angles about the central halide are less than $360^{\circ}\left(349.2^{\circ}, 353.7^{\circ}\right.$, and $343.2^{\circ}$ respectively). Herein, the possible limiting structures of $3 \mathrm{C}$ metal complexes are identified and the methodology used to classify three-coordinate structures is outlined. The classification scheme is then used to describe the

Dalton Transactions, Vol 44 (2015): pg. 15408-15412. DOI. This article is (C) Royal Society of Chemistry and permission has been granted for this version to appear in e-Publications@Marquette. Royal Society of Chemistry does not grant permission for this article to be further copied/distributed or hosted elsewhere without the express permission from Royal Society of Chemistry. 
geometry about three-coordinate silver(I) centres in two complexes of the new $\mathrm{N}$-donor ligands, $\mathrm{H}_{2} \mathrm{NC}_{6} \mathrm{H}_{4} \mathrm{C}_{6} \mathrm{H}_{4} \mathrm{CHpz}_{2}$ ( $\mathrm{pz}=$ pyrazol-1-yl), L1, and 2-ferrocenyl-4,5-di(2-pyridyl)imidazole, L2 (left and right of Chart 1). Results of a search of three-coordinate metal complexes in the Cambridge Structural Database (CSD) are also examined to ascertain the frequency of occurrence of the most common and of limiting "high symmetry" structures.

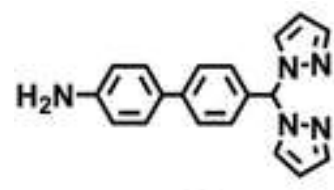

L1

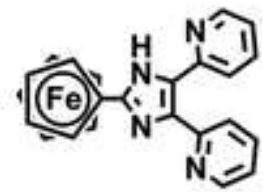

L2

Chart 1

Chart 1 New heteroditopic ligands used in this work.

When four atoms reside in a plane, the planar projections will adopt either triangular or quadrilateral shapes between two hypothetical (chemically impossible) linear extremes (Closed $\mathrm{Y}$ or Closed Arrow), exemplified in Fig. 1 and, more completely, in Fig. S4S6. \pm The three angles about the centre atom in $3 \mathrm{C}$ structures will be given from largest to smallest angle (when possible) by $a / \beta / \gamma$. The $T$ shape (180/90/90, top row centre Fig. 1) and Trigonal plane (120/120/120) are well known. In between the T-shape and Trigonal plane are "Compressed $Y^{\prime} s^{\prime \prime}\left(120<a<180,3^{\text {rd }}\right.$ structure, bottom row, Fig. 1) or, "a-dominant $Y$ 's", if monoclinic $(\beta=\gamma)$. Similarly between the Trigonal plane and Closed $Y(180 / 180 / 0)$ are "Extended $Y$ " shapes $\left(0<y<120,2^{\text {nd }}\right.$ structure, bottom row, Fig. 1$)$ or " $Y$-dominant $Y$ 's" if $a=\beta$. A previously unrecognized shape of relevance to $\mathrm{ClF}_{3}$ are Arrows. Arrows are identified by the angular relation, $180^{\circ}>a=\beta+$ $Y$. If one starts from a T-shape and moves both arms "down" $45^{\circ}$ then a "Normal Arrow" (90/45/45) with a quadrilateral projection is produced. In between the T-shape and the Normal Arrow are "Expanded" Arrows while between the Normal and Closed Arrows are "Compressed" Arrows. It is noted that the top row of Fig. 1 represents a series of highest-symmetry planar structures with three (trigonal) or two (monoclinic) identical angles. Since the $\beta$-values of this series have a continuous range from 180 to $0^{\circ}$, these (or the ratio $\beta / 180$ ) could comprise a "YTA index" to describe the "Y-", "T-", or "Arrow-" 
character of planar (trigonal and) monoclinic systems. Most systems, however, are triclinic with three different angles. If one starts with a Tshape and moves the 'right' arm up $30^{\circ}$ then a triclinic "Orthogonal $Y^{\prime}$ shape (with angles 150/120/90) is produced (bottom right, Fig. 1). The Orthogonal $Y$ shape (but wholly rotated $120^{\circ}$ ) could also be produced by moving one arm of a trigonal plane $30^{\circ}$. Thus, the $150 / 120 / 90$ shape is halfway between a T-shape and a trigonal plane, and is a "high symmetry" point in the 2D, 3C shape-space. There are other types of triclinic $Y$-shapes that are derived from the T-shape, but by moving the vertical leg "left" or "right". Thus, the structure on the bottom left of Fig. 1 (180/150/30) is an Oblique $Y$ and can be derived from either a Closed $Y$ or a T-shape. Fig. S6士 and its accompanying text in the ESI \pm details how the obliqueness of a triclinic system is measured. As can be seen in Fig. 1 or $S 4, \pm$ there are numerous other special shapes that are produced by simple "one-arm" or "two-arm" distortions of ideal shapes and all of these, as well as the above examples, provide the basis for the "ideal structures" found in the planar classification scheme that is embedded in the ESI spreadsheet, \pm as discussed later.

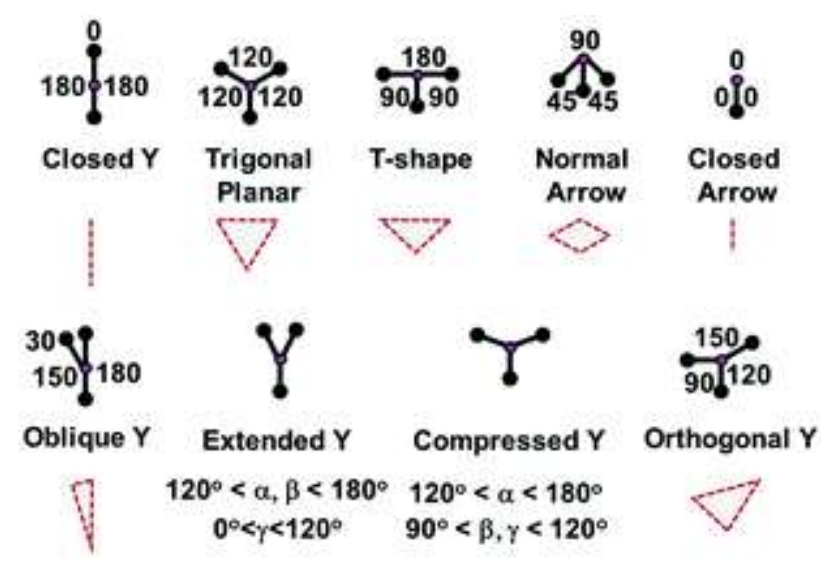

Figure 1

Fig. 1 Representative arrangements of atoms in planar $3 \mathrm{C}$ structures. The numbers are interatomic angles. Projections of atoms on plane give grey polygons (or just lines) with red dashed lines.

If the centre atom of a trigonal plane is pulled "upward" and normal to the plane, then right trigonal pyramids $\left(a=\beta=\gamma<120^{\circ}\right.$ )

Dalton Transactions, Vol 44 (2015): pg. 15408-15412. DOI. This article is (C Royal Society of Chemistry and permission has been granted for this version to appear in e-Publications@Marquette. Royal Society of Chemistry does not grant permission for this article to be further copied/distributed or hosted elsewhere without the express permission from Royal Society of Chemistry. 
are formed where the apex of the pyramid lies directly above the middle of the base triangle (Fig. 2). The relative positions of the incircle and circumcircle of a base triangle defines the type and aids in finding metrics of different pyramids. The origin of an incircle, $\mathrm{O}_{i c}$, is found at the point of intersection of three lines that bisect each internal angle. The origin of a circumcircle, $\mathrm{O}_{\mathrm{cc}}$, is the point where three perpendicular bisectors of the base edges meet. The radii of the incircle and circumcircle are $r_{\text {ic }}$ and $r_{c c}$. The origins $\mathrm{O}_{\mathrm{cc}}$ and $\mathrm{O}_{\mathrm{ic}}$ coincide in a right trigonal pyramid but do not coincide in other pyramids (vide infra). The projection of the sides, $e$, on the base triangle coincides with the three lines drawn from $\mathrm{O}_{\mathrm{cc}}$ to each vertex of any base triangle. If the edges of the side triangles, e, are of unit length then the pyramid height, $h$, and the incline angle of the side relative to the base, $\varphi 1_{\text {incl, }}$ can be calculated from the apex angles via the slant height, $s 1=\cos (a / 2)$ and the base length, $b 1=2 \sin (a / 2)$ as fully detailed in the ESI. \pm For a right trigonal pyramid, $\varphi 1_{\text {incl }}$ is less than $90^{\circ}$. Other types of trigonal-pyramids can be characterized by the number of identical angles about the apex. Thus, cases where $a=\beta \neq$ $y$ or $a \neq \beta=y$ are monoclinic pyramids whereas those with $a \neq \beta \neq \gamma$ are triclinic pyramids. Monoclinic pyramids have $\mathrm{O}_{\mathrm{cc}}$ separated from $\mathrm{O}_{\mathrm{ic}}$ in the base triangle plane in only one direction, perpendicular to the base triangle edge that is opposite of the unique angle. Triclinic pyramids have $\mathrm{O}_{\mathrm{cc}}$ separated from $\mathrm{O}_{\mathrm{ic}}$ in two directions, both parallel and perpendicular to the base triangle edge that is opposite of the side triangle with a as an apex angle. As illustrated in Fig. 3, monoclinic or triclinic pyramids can further be classified as either "acute", "normal", or "obtuse" if $\mathrm{O}_{\mathrm{cc}}$ resides, respectively, either inside, directly on, or outside of the base triangle edges (Fig. 3). As such, the incline angles are less than, equal to, and greater than $90^{\circ}$ for an acute, a normal, and an obtuse pyramid, respectively. Similar to right trigonal pyramids, other pyramids can be created by taking the centre atom of a monoclinic or triclinic planar structure and pulling "upward" thereby decreasing apex angles proportionally, according to the Law of Sines, until a linear limit 0/0/0 (Closed Arrow) is reached. Alternatively, some pyramids can be formed by taking a planar structure and pulling two of the 'arms' together until a planar folded limit is reached $\left(a_{\text {fold, }}\right.$ lim $=\beta$ - Y, see Fig. S7 \pm and accompanying text). For example, if the two horizontal arms of a T-shape (180/90/90) are pulled out of the plane while maintaining two angles at $90^{\circ}$, the third angle a would decrease

Dalton Transactions, Vol 44 (2015): pg. 15408-15412. DOI. This article is (c) Royal Society of Chemistry and permission has been granted for this version to appear in e-Publications@Marquette. Royal Society of Chemistry does not grant permission for this article to be further copied/distributed or hosted elsewhere without the express permission from Royal Society of Chemistry. 
from $180^{\circ}$ to $90^{\circ}$ until a triorthogonal pyramid $(90 / 90 / 90)$ is reached. Then further reduction to $a_{\text {fold, }} \lim =\beta-\gamma=0$, would cause the original T-shape to be completely folded into two dimensions 90/90/0. Thus, pyramids can be classified both according to their metrics and by their relation to planar structures.


Figure 2

Fig. 2 Left: Perspective drawing of a trigonal pyramid of height $h$, slant height s1, side edge length, e. Right: Projection of the base triangle (right) of edge length b1 and internal angle $A^{\prime}$. The circumcircle of the base triangle with radius $r_{c c}$ is green, the incircle with radius $r_{\text {ic }}$ is black.
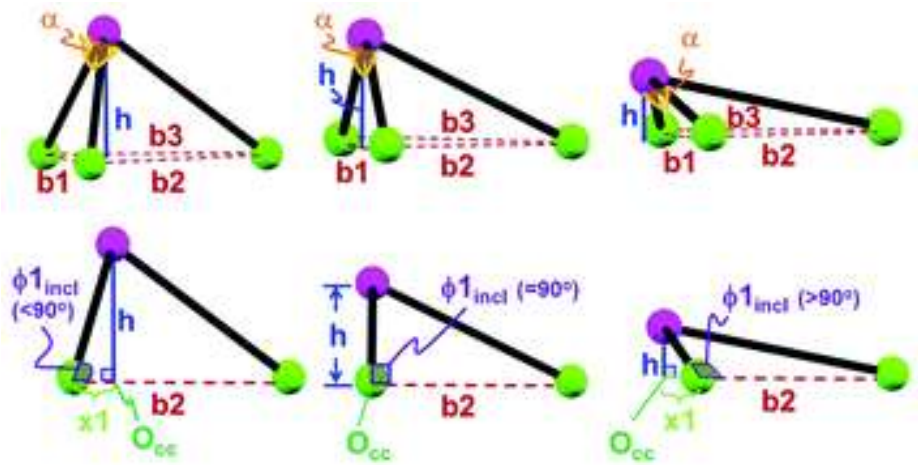

Figure 3

Fig. 3 Perspective (top) and side (bottom) views showing "acute" (left), "normal" (center), and "obtuse" (right) pyramids. The red dashed lines are the base triangle. b1 is the length of a base triangle edge that is also opposite of apex angle a (b2 is opposite of apex angle $\beta$ ). Blue line $h$ is the height of the pyramid. $O_{c c}$ is the origin of the base triangle's circumcircle. $\varphi 1_{\text {incl }}$ is the incline of the side triangle (with a apex angle) with respect to base triangle. $x 1=$ perpendicular distance from $b 1$ to $\mathrm{O}_{\mathrm{cc}}$.

In order to identify $3 \mathrm{C}$ structure types from angular values, a method loosely based on Alvarez's ${ }^{12}$ "shape-space" approach (for four-

Dalton Transactions, Vol 44 (2015): pg. 15408-15412. DOI. This article is (C) Royal Society of Chemistry and permission has been granted for this version to appear in e-Publications@Marquette. Royal Society of Chemistry does not grant permission for this article to be further copied/distributed or hosted elsewhere without the express permission from Royal Society of Chemistry. 
to nine-coordinate structures) is used. Basically, the three input angles are compared to those of a host of ideal shapes (planar or pyramidal) and those angular values that deviate the least from ideal are called a match. The minimization function follows the form of eqn (1). Here, a, $\beta$, and $y$ are the angles to be tested, whereas $a_{i d}, \beta_{i d}, Y_{i d}$ are the

Equation 1

$$
\begin{aligned}
\operatorname{Min}\left(^{\circ}\right)= & (3)^{-1 / 2}\left(\left[\left(\alpha-\alpha_{i d}\right)^{2}+\left(\beta-\beta_{i d}\right)^{2}\right.\right. \\
& \left.+\left(\gamma-\gamma_{i d}\right)^{2}\right]^{1 / 2}
\end{aligned}
$$

ideal angles of the "high-symmetry" shapes to which the input angles are compared. The constant $(3)^{-1 / 2}$ is a normalization factor. The ESI includes a spreadsheet that allows users to input angular values and the number of atoms in a plane. The resulting output provides the name and various metrics of the ideal shape that most closely matches the input values.

During the course of studies on the coordination chemistry of redox active heteroditopic ligands, we prepared silver(I) complexes $[\mathrm{Ag}(\mathbf{L 1})]\left(\mathrm{BF}_{4}\right), \mathbf{1}$, and $[\mathrm{Ag}(\mathbf{L 2})]\left(\mathrm{SbF}_{6}\right) \cdot \mathrm{CH}_{2} \mathrm{Cl}_{2}, \mathbf{2}$. Both $\mathbf{1}$ and $\mathbf{2}$ crystallized as solvates with complex cations that were cyclic dimers in the solid state. In these dimers, the $\mu-\mathrm{K}^{2} \mathrm{~N}, \mathrm{~K}^{1} \mathrm{~N}$-ligands spanned two three-coordinate silver centres (top of Fig. 4) where the respective long Ag...Ag separations of 10.845 and $4.997 \AA$ precluded any direct intermetallic interactions. Importantly, the silver centres in $\mathbf{1}$ were planar with sum of angles either exactly or very nearly $360^{\circ}$ ( $\Sigma \Varangle^{\prime} \mathrm{s}(\mathrm{Ag} 1), 359^{\circ} ;(\mathrm{Ag} 2), 360^{\circ}$ ) whereas the symmetry-equivalent silver(I) centres in $\mathbf{2}$ were decidedly pyramidal ( $\Sigma 4^{\prime} \mathrm{s}(\mathrm{Ag} 1): 340^{\circ}$ ) and none were ideal T-shape, trigonal planar, nor trigonal pyramidal (with three identical angles). So, these complexes provide reasonable examples of the need for an advanced classification system. For $\mathbf{1}$, Ag2 is planar with angular values $164 / 112 / 84$, most closely matching a "1/3 $\beta$-compressed Orthogonal $Y$ " (160/110/90; $1 / 3$ of the way from an Orthogonal $Y$ to a T-shape) but with 4,2 , and $6^{\circ}$ deviations in $a, \beta$, and $y$ for $a$ Min $=4.32^{\circ}$. The geometry about Ag1 in $2(146 / 121 / 73)$ is an acute triclinic pyramid. The pyramid is guaranteed to be acute since the sum of any combination of two apex angles is greater than $180^{\circ}$. 
This pyramid most closely matches that derived by taking a $\mathrm{Y}^{-}$ Compressed Semi-Orthogonal $Y(165 / 120 / 75)$ and folding the two arms that flank angle a by $20^{\circ}(7 \%)$, effectively lifting the centre atom 0.226 units out of the plane of ligand atoms, leaving only 1,1 , and $2^{\circ}$ deviations in $a, \beta$, and $\gamma$, respectively, from the experimental angles, thereby giving a Min $=1.41^{\circ}$.
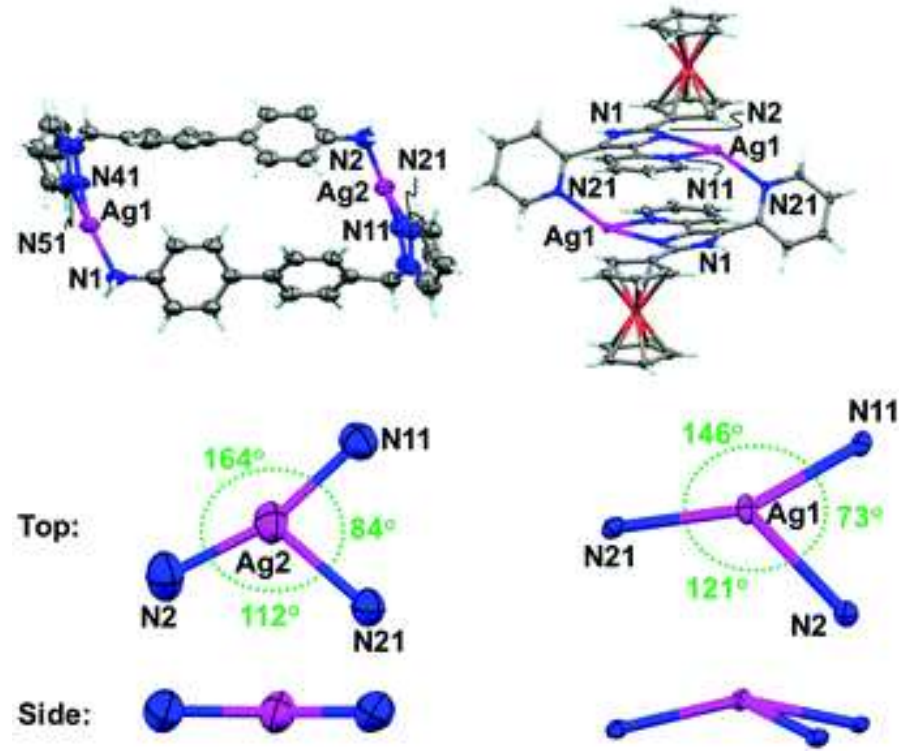

Side:

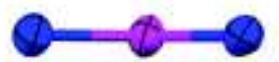

Figure 4

Fig. 4 Various views of the structures of the cations in $\left[A g_{2}(\mu-\mathbf{L 1})_{2}\right]\left(B F_{4}\right)_{2}, \mathbf{1}$, and $\left[\mathrm{Ag}_{2}(\mu-\mathbf{L 2})_{2}\right]\left(\mathrm{SbF}_{6}\right)_{2}, \mathbf{2}$. Thermal ellipsoids at the $50 \%$ probability level.

The non-ideal angles about silver in $\mathbf{1}$ and $\mathbf{2}$ prompted a query into the frequency of occurrence of various geometries in $3 \mathrm{C}$ silver or other metal complexes. The CSD search results (see ESI $\_$) identified 18001 instances where any metal was (only) bound to three nonmetals, cases referred to as $\mathrm{ME}_{3}$. Of these, nearly $15 \%$ (2751) were $3 \mathrm{C}$ silver complexes. If one allows a $2^{\circ}$ variation in $a, \beta, \gamma$ to account for rounding errors (some $\Sigma x^{\prime} s=361^{\circ}$ ) or possible experimental uncertainties then a $\Sigma \Varangle^{\prime} \mathrm{s} \geq 354^{\circ}$ would represent a "planar" complex. Under these criteria, $63 \%$ of all $3 \mathrm{C}$ metal complexes and $82 \%$ of $3 \mathrm{C}$ silver complexes are planar (Fig. 5). Thus, compound $\mathbf{2}$ represents a rather rare example of pyramidal $3 \mathrm{C}$ silver. Contrary to expectations based on general and inorganic chemistry texts, very few $3 \mathrm{C}$

Dalton Transactions, Vol 44 (2015): pg. 15408-15412. DOI. This article is (C) Royal Society of Chemistry and permission has been granted for this version to appear in e-Publications@Marquette. Royal Society of Chemistry does not grant permission for this article to be further copied/distributed or hosted elsewhere without the express permission from Royal Society of Chemistry. 
complexes actually exhibit ideal structures. While the most common $3 \mathrm{CME}_{3}$ geometry is indeed trigonal planar $\left(\mathrm{a}=\beta=\gamma=120 \pm 2^{\circ}\right)$, this constitutes only about $3.8 \%(679 / 18001)$ of all $3 C$ structures. Similarly, only $\sim 0.05 \% 3 \mathrm{CME}_{3}$ complexes are T-shape $\left(\mathrm{a}=180 \pm 2^{\circ}\right.$, $\beta=\gamma=90 \pm 2^{\circ}$ ). The most common angles for pyramidal $3 \mathrm{C} \mathrm{ME}_{3}$ complexes are $a=96 \pm 2^{\circ}, \beta=95 \pm 2^{\circ}, \gamma=94 \pm 2^{\circ},(549 / 18001$, $3.0 \%$ ) corresponding to a $13.6 \%$ closed trigonal pyramid (or near triorthogonal pyramid); only $0.3 \%$ are "ideal" trigonal pyramidal ( $a=$ $\left.\beta=Y=110 \pm 2^{\circ}\right)$. A large majority of $3 C$ structures are $Y$-shape. For instance, there are (4946/18 001) $27.5 \%$ of cases that fit under the general category of 'Extended $Y^{\prime}$ shapes $\left(120 \pm 2^{\circ}<a \& \beta<180 \pm\right.$ $2^{\circ}, y<120 \pm 2^{\circ} ; \Sigma \Varangle^{\prime} s \geq 354^{\circ}$; i.e., regardless of asymmetry or obliqueness) while another (4481/18 001) 24.9\% are 'Compressed $Y^{\prime}$ shapes $\left(a>120^{\circ} \pm 2 ; 90 \pm 2^{\circ}<\gamma \& \beta<120 \pm 2^{\circ} ; \sum \Varangle^{\prime} \mathrm{s} \geq 354^{\circ}\right.$, again ignoring asymmetry). There are also 46 examples or $0.3 \%$ of $\mathrm{ME}_{3}$ cases with arrowhead distortions $\left(\mathrm{a}=\beta+\mathrm{Y}\right.$, $\sum 4^{\prime} \mathrm{s}<360^{\circ}$, and $\mathrm{h} \sim$ $0)$, a geometry that has not been well recognized in texts previously but is important in hypervalent halide compounds. ${ }^{13}$

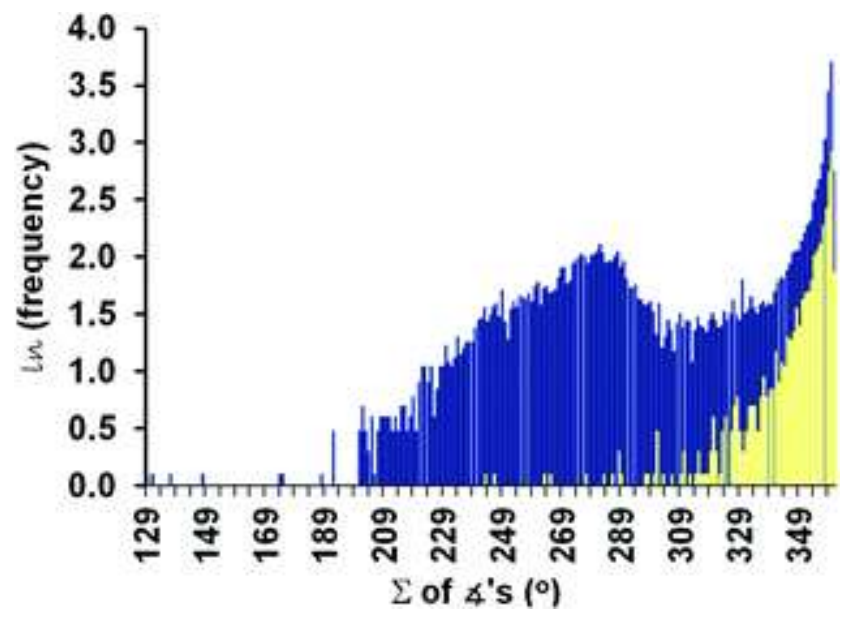

Figure 5

Fig. 5 Histograms showing the In(frequency of occurrence) of the $\Sigma x^{\prime} \mathrm{s}$ in $3 \mathrm{C}^{\mathrm{ME}} \mathrm{ME}_{3}$ complexes (blue, 18001 total) or 3C Ag (yellow, 1812 total) in the CSD. Single instances were scaled to 0.1 on the In scale.

Since most metal complexes have coordination numbers between 4 and 6 , there have been extensive studies regarding their structural classification. The CSD search performed here revealed that

Dalton Transactions, Vol 44 (2015): pg. 15408-15412. DOI. This article is (C) Royal Society of Chemistry and permission has been granted for this version to appear in e-Publications@Marquette. Royal Society of Chemistry does not grant permission for this article to be further copied/distributed or hosted elsewhere without the express permission from Royal Society of Chemistry. 
$3 \mathrm{C}$ metal complexes are relatively rare, but significant, accounting for $\sim 5 \%(18001 / 372280)$ of all $\mathrm{ME}_{n}(\mathrm{n}=2-6)$ complexes. Of these, most structures are not adequately described by ideal trigonal planar, pyramidal, or T-shape geometries. So, to address issues with structural description of three coordinate complexes, we developed a system for their classification based on angular values and knowledge of the number of atoms in the plane (available from modern crystallographic software). This classification system was implemented into a spreadsheet found in the ESI \pm whereby users can input angular data to extract names and metrics of the planar triangle or pyramid. Since most $\mathrm{ME}_{3}$ complexes are those with metals from groups 11-13 (56\%, 10 000/18 001), it is expected that this new classification system will be most helpful for describing the coordination geometries in complexes of these groups, especially the highly variable ones of three-coordinate silver(I).

JRG thanks Prof. Q. Timerghazin for helpful discussions, the NSF (CHE-0848515) and Marquette University for funding. KJB thanks the U.S. Dept. of Transportation's Dwight David Eisenhower Transportation Fellowship Program (DDETFP) and the WSSU Research Initiation Program (RIP) for funding.

\section{References}

${ }^{1}$ R. B. King, Coord. Chem. Rev., 2000, 197, 141 R. B. King, Inorg. Chem., 1981, 20, 363.

${ }^{2}$ A. Avdeef and J. P. Fackler Jr., Inorg. Chem., 1975, 14, 2002; D. L. Kepert, Inorg. Chem., 1972, 11, 1561.

${ }^{3}$ A. W. Addison, T. N. Rao, J. Reedijk, J. van Rijn and G. C. Verschoor, J. Chem. Soc., Dalton Trans., 1984, 1349.

${ }^{4}$ L. Yang, D. R. Powell and R. P. Houser, Dalton Trans., 2007, 955.

${ }^{5}$ M. H. Reineke, M. D. Sampson, A. L. Rheingold; and C. P. Kubiak, Inorg. Chem., 2015, 54, 3211.

${ }^{6}$ J. R. Gardinier, J. S. Hewage and S. V. Lindeman, Inorg. Chem., 2014, 53, 12108 .

${ }^{7}$ G. A. Lawrance, Introduction to Coordination Chemistry, John Wiley \& Sons Ltd, West Sussex, UK, 2010, Ch 4; T. L. Brown, H. E. Lemay Jr., B. E. Bursten and C. J. Murphy, Chemistry: The Central Science, Pearson Education Inc, Upper Saddle River, NJ, 10th edn, 2006, Ch. 9.

8]. R. Gispert, Coordination Chemistry, Wiley-VCH Verlag GmbH \& Co., Weinheim, 2008, Ch. 3.

Dalton Transactions, Vol 44 (2015): pg. 15408-15412. DOI. This article is @ Royal Society of Chemistry and permission has been granted for this version to appear in e-Publications@Marquette. Royal Society of Chemistry does not grant permission for this article to be further copied/distributed or hosted elsewhere without the express permission from Royal Society of Chemistry. 
NOT THE PUBLISHED VERSION; this is the author's final, peer-reviewed manuscript. The published version may be accessed by following the link in the citation at the bottom of the page.

${ }^{9}$ D. F. Smith, J. Chem. Phys., 1953, 21, 609.

${ }^{10}(a)$ J. V. Carey, P. A. Chaloner, P. B. Hitchcock, T. Neugebauer and K. R. Seddon, J. Chem. Res., 1996, 358, 2031; (b) E. M. Archer and T. G. D. van Schalkwyk, Acta Crystallogr., 1953, 6, 88.

${ }^{11}$ R. Minkwitz and M. Berkei, Inorg. Chem., 1999, 38, 5041.

${ }^{12}$ D. Casanova, J. Cirera, M. Llunell, P. Alemany, D. Avnir and S. Alvarez, J. Am. Chem. Soc., 2004, 126, 1755; S. Alvarez, P. Alemany, D. Casanova, J. Cirera, M. Llunell and D. Avnir, Coord. Chem. Rev., 2005, 249, 1693.

${ }^{13}$ This $\mathrm{ME}_{3}$ search did not include iodine as the central atom, $M$, an element for which the arrowhead geometry (restricting $h<0.06 \AA$ ) is most prevalent with 147 of 277 (or $53 \%$ ) of occurrences.

\section{Footnote}

${ }^{\dagger}$ Electronic supplementary information (ESI) available: Experimental procedures, crystal data, other characterization data, details of CSD search, further discussion of triangle and pyramid metrics, interactive spreadsheet with classification system. CCDC 1400747 for 1 and 1400748 for 2. For ESI and crystallographic data in CIF or other electronic format see DOI: $10.1039 / \mathrm{c5} d t 02773 \mathrm{j}$

Dalton Transactions, Vol 44 (2015): pg. 15408-15412. DOI. This article is (C) Royal Society of Chemistry and permission has been granted for this version to appear in e-Publications@Marquette. Royal Society of Chemistry does not grant permission for this article to be further copied/distributed or hosted elsewhere without the express permission from Royal Society of Chemistry. 